\title{
A Comparative Study on Life Cycle Assessment of Typical Wood base Furniture
}

\author{
Shuyi Wang ${ }^{1,2, a}$, Daizhong Su ${ }^{2, b}$ Shifan Zhu ${ }^{3, c}$ \\ ${ }^{1}$ Scool of Art and Design, Heilongjiang Institution of Technology, No.999 Hongqi Street, Harbin, \\ China \\ ${ }^{2}$ School of Architecture Design and the Built Environment, Nottingham Trent University, NG1 \\ 4FQ,Uk \\ ${ }^{3}$ Department of Industrial Design, College of Mechanical Engineering and Electronics, Harbin \\ Engineering University, No.145 Nantong Street, Harbin, China \\ aalice.399@hotmail.com, bdaizhong.su@ntu.ac.uk, 'zhushifan@hrbeu.edu.cn
}

Keywords: Life Cycle Assessment (LCA); Environmental Impact; furniture; wood products.

Abstract. The assessment of environmental performance was carried out to identify the environmental impact of three typical solid wood based furniture: A beech wood desk (P1), A white oak-and-fabric sofa (P2), A rubber wood wardrobe (P3). A field research of company' s manufacturing plant was conducted in order to investigate the production process as well as collect the inventory data under assessment. Life cycle environmental impact were assessed throughout subjects' life cycle by utilizing LCA software tool (Simapro) and Eco-indicator 99 method. The damage impact under study including three main categories: Ecosystem Quality, Human Health, Resources. The results showed that P1 has the smallest negative impact (22.1 pt) compares to P2(57.3 pt) and P3 (142 pt). Hot spots and key environmental processes were also identified. Moreover, key processes and impact categories as well as damage per unit mass had been addressed and analyzed respectively. Improvement alternatives were suggested to improve environmental performance of solid wood base furniture at the end of the article.

\section{Introduction}

Furniture products are widely used in our daily life. In 2015, world furniture market was worth US\$ 455 billion. The volume of export trade in China reached 52.8 billion US dollars. Furniture product has become promising and one of the most leading export merchandises in China [1]. However, there are growing concern about export volume in the future of furniture sector. This may attribute to many reasons, such as lack of study and implementation towards sustainable furniture design and manufacture; The problem with reach the international standard of harmful emissions (mainly formaldehyde emission) in manufactured furniture products; The former extensive economic growth model has impeded the sustainability of furniture sector, etc.. Therefore, it is an urgent task to conduct furniture related study in life cycle environmental impact point of view and thus to guide companies accelerate their entrance into international market of green furniture products.

Life cycle assessment (LCA) have proved to be an effective methodology to assess the the environmental impact of materials, processes, products, and resent years become an important tool to support decision-making in product innovations, government procurements, and eco-label declarations. Wood is one of the most frequent used material in furniture sector. Studies have shown that wood (especially wood from sustainable forest) has lower environmental impact among other materials applied in furniture like metals and plastics $[2,3]$.

There have been considerable amount of literature regarding wood-based products and furniture in LCA perspective. Among the literature, there are studies focused on eco wooden material selection and assessment, such as Bovea M.D. et al. conducted comparative LCA on standard particle board, low formaldehyde particle board and fiberboard [4], González-García et al. assessed hardboards and green hardboards $[5,6]$. There are also studies using LCA and as a tool on furniture innovation and life cycle comparison of furniture products. Examples could be found in Taylor and Sara González-García 
et al. [7,8] where key environmental impact processes and scenario were identified and improvement alternatives were proposed. However, Most studies are focused on the comparison of different kind of materials or product processes, such as comparison between wood base boards and solid wood or wood with other materials. Limited literature are regarding comparison between solid wood-base materials and/or with combinations of other materials and processes and thus provide evidence to support furniture innovation and material choosing.

This paper aims to identify the environmental impacts and "hot spot" processes of three solid wood base furniture by conducting LCA and comparing analysis, so as to provide insights on material choosing and decision-making for eco-friendly furniture innovation.

\section{Environmental Assessment Study}

Goal and Definition. This assessment aims to identify the environmental impacts (to Human Health, Ecosystem Quality And Resource) of three typical solid wood-base furniture: A beech wood desk (P1), A white oak-and-fabric sofa (P2), A rubber wood wardrobe (P3). One Chinese furniture company located in Tsingtao (Shandong Provence of China) has been selected as representative to provide related production inventory data under study. The company is a prestigious and leading producer of solid wood in China, they have history more than 60 years and willing to reform their production pattern so that they could be better adapted for the growing green furniture market. The selection of the tree access subjects are based on following reasons:

The furniture products under study are the most commonly used products in daily life and share similar manufacturing processes with other furniture production. The three products both have similarity and distinctiveness. The base material of P1, P2, P3 are solid wood; P1 and P3 are fully made of solid wood but with different in mass and wood species as well as suppliers; P2 combines solid wood and fabrics while with the total mass in between P1 and P3, thus ensure comparability of the LCA results.

Functional Unit. The subjects under study are $P 1$ two drawer beech desk $(50.7 \mathrm{~kg}), P 2$ white oak-and-fabric sofa $(96.1 \mathrm{~kg}), P 3$ rubber wood four-door wardrobe $(324.6 \mathrm{~kg})$. The main structure and material are solid wood. For P2 in which includes macromolecule material plastic and Cotton blended fabric as infilling and pillow case material respectively. All separate components are connected with screws, plastics are used in accessory member, packaging etc.. Fig. 1 illustrates the function units and corresponding structures of the subjects under assess.

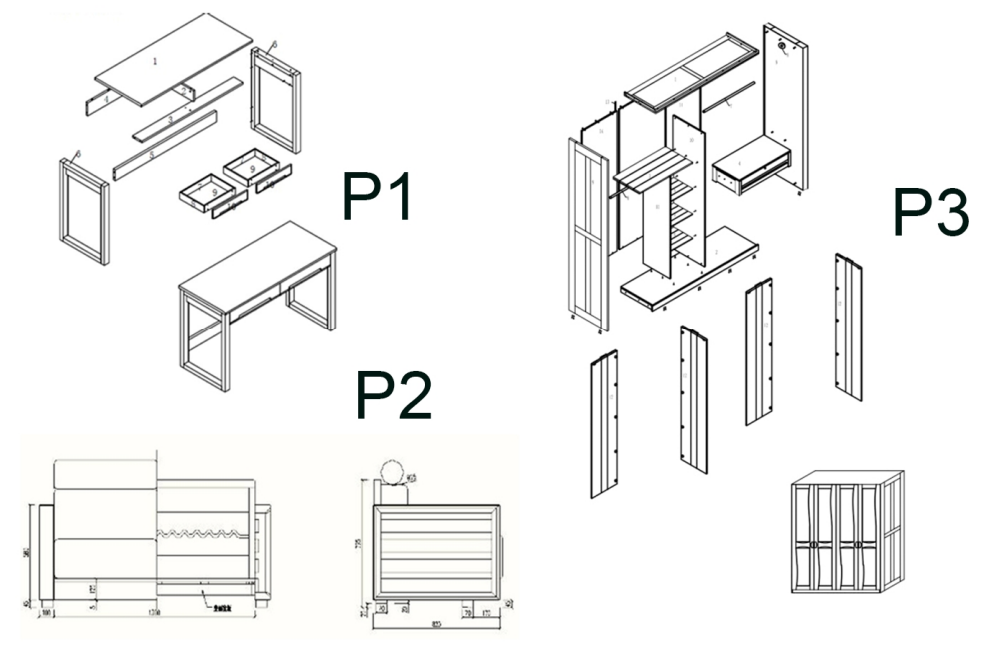

Fig.1 Function units under study

System Boundary. A field research of company's manufacturing plant was conducted in order to investigate the production process of furniture subjects. Three main procedure were identified in the production stage, namely assembly, surface treatment and packaging. During assemble, solid wood is 
cut and made into given size and jointed; surface treatment includes procedure like sanding and painting; packaging is the last section of production before furniture delivered.

Figure 2, 3 demonstrate system boundaries of P1, P2, P3. As P1 and P3 are fully made of solid wood as stated above, therefore they share the same production process as well as system boundary. As shown in Fig. 1, the boundary including stages trough the life cycle of P1 and P3, from raw material extraction, production (related backstage and forestage processes), all transportation associated in their life cycle as well as waste disposal are all within the system boundary. Energy consumption such as heating, electricity together with water consumption are also taken into account of the assessment. For P2, the system boundary is at the base of P1 and P3. In addition, the production of textile and infilling materials and its related assembly process are included(Fig. 3).

Since furniture barely need energy input and the maintenance data are out of reach, therefore use phase are excluded from system boundary. Besides, end of life data is uncertain, so this stage is also been excluded in the assessment.

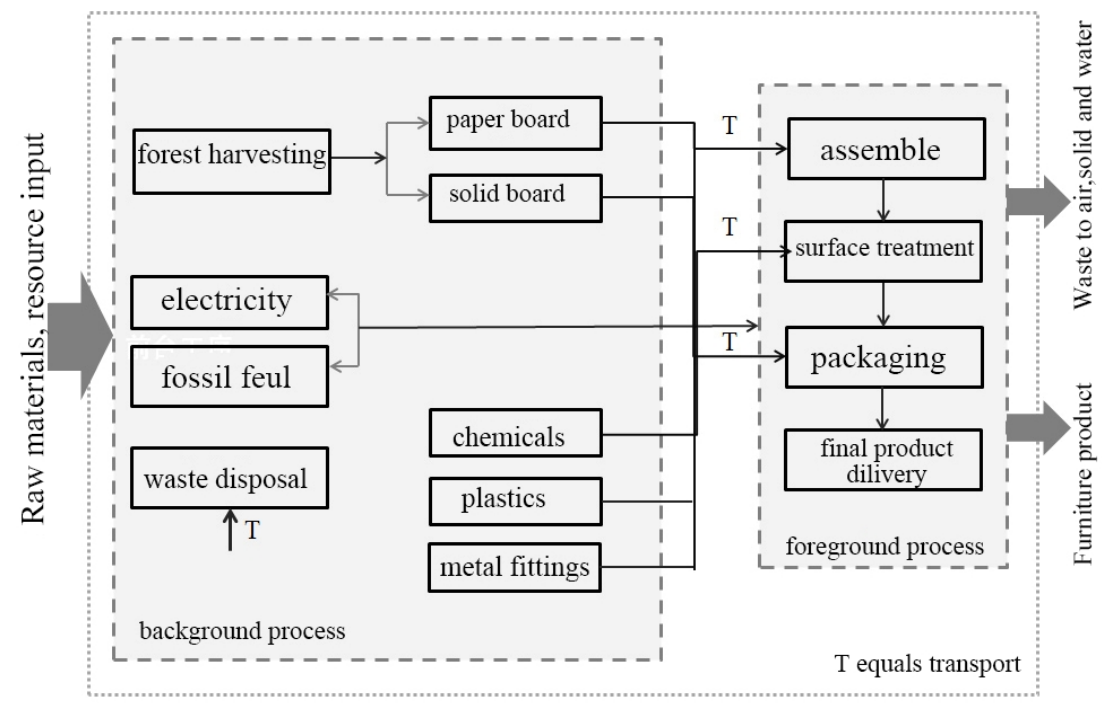

Fig. 2 System boundary of P1 and P3

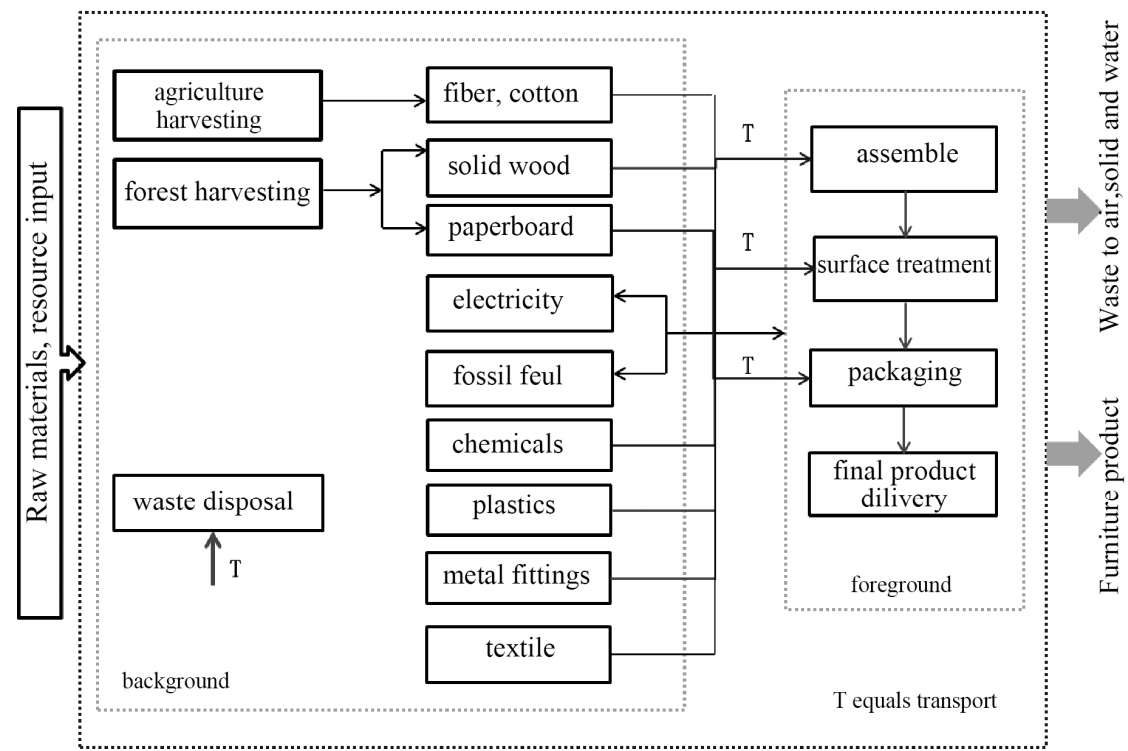

Fig. 3 System boundary of P2

Inventory Data. Most foreground data is acquired from on-site measurement or from annual/quarterly data provided by the producer under study and calculated. The volume of usage in wood, chemicals, electricity consumption are calculated for individual furniture. Material transport, end product transport and waste transport information (distance, type of transport and vehicle model) 
are from the average calculation of the distance of supplier and retailer which provided by company's logistics department.

The background inventory data related to processes like raw material extraction, plastic production, fabric production, production of electricity, etc.. are from Ecoinvent database. A brief description of life cycle input-output inventory data are listed in Table 1.

Table 1 Life Cycle Input-Output Inventory Data

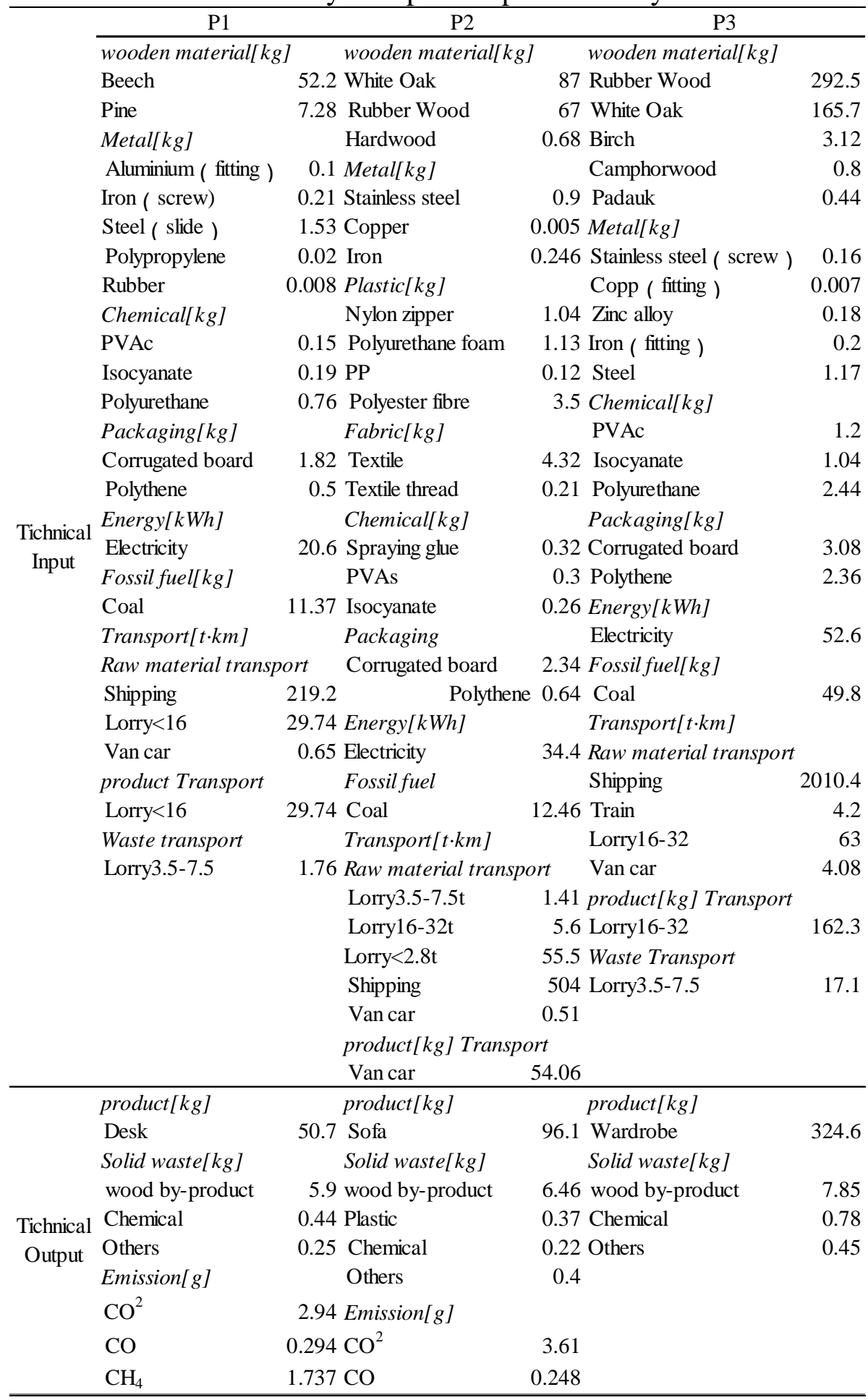

Allocation. Since the furniture company produces furniture in different character and mass. Allocation procedure is needed to allocate the data of energy consumption, packaging material usage as well as output wastes. In this study, related data was allocated according to products' mass on an annual production base. 
Life Cycle Assessment. LCA was conducted of three subjects by utilizing Simapro 7.3 as software tool and Eco-indicator 99 (EI99) as assessment method. EI99 is a damage oriented method which focus on impact assessment towards three main categories: Ecosystem Quality, Human Health, Resources [9]. The subcategories of impact assessed including: Land Use, Fossil Fuel, Mineral, Ozone Layer, Carcinogens, Eco Toxicity, Acidification, Eutrophication, Respiratory Organics, Respiratory Inorganics, Climate Change, Radiation.

The results of Environmental performance are shown in Table 2. According to the results, the total impact index were P1 $22.1 \mathrm{pt}, \mathrm{P} 257.3 \mathrm{pt}, \mathrm{P} 3142 \mathrm{pt}$, the indexes indicates that P1 has the smallest impact index (I) through its life cycle compares to $\mathrm{P} 2$ and $\mathrm{P} 3$, thus $\mathrm{P} 1_{\mathrm{I}}<\mathrm{P} 2_{\mathrm{I}}<\mathrm{P} 3_{\mathrm{I}}$. For the impact index of subcategories under study, The dominant impact is Land Use category (P1 10.62, P2 24.61, P3 86.97) followed by Respiratory Inorganics (P1 4.7, P2 13, P3 25) and Fossil Fuel category (P1 4.3 P2 12.5 and P3 18.3)..

\section{Key Environmental Process Interpretation and Result Analysis}

Fig. 4 summarized the identified (from LCA) "hot spots" and key environmental processes of the three subjects. As presents in the Fig., wooden material production, raw material transportation and electricity production are the key environmental impact processes in P1 and P3; wooden material production, raw material transportation and textile production are the key processes that contribute the most to P2's environmental impact. The production of wooden material proved to be the "hot spot" process in three subjects' life cycle environmental impact profile: P1 (68\%), P2 (50\%) and P3 (88\%) as solid wood is the major material used in the three products especially in P1 and P3. Apart from this, transportation of raw materials presents to be the other environmental issues shared within the three product which contribute $17 \%, 14 \%$ and $6 \%$ respectively to their environmental impact. The reason was the raw wood(Beech, White Oak and Rubber wood) are mostly imported and delivered by shipping with a far distances thus lead to large impact on Resources and Human Health. The production of Textile is the second key process to P2's impact index (25\%), in which can be ascribed to the impact generated from cotton production, floating dust during production, chemical additives, etc..

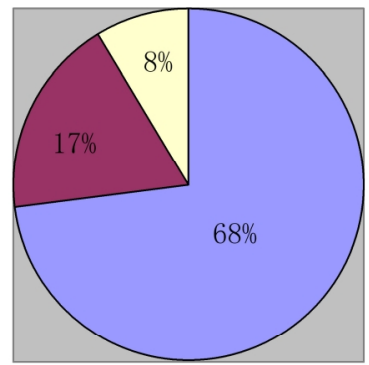

P1

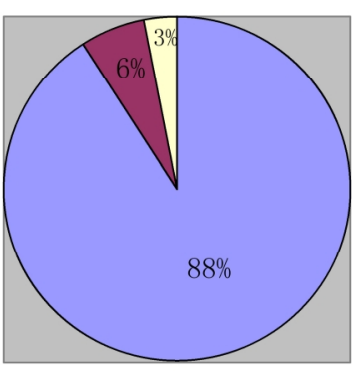

P3

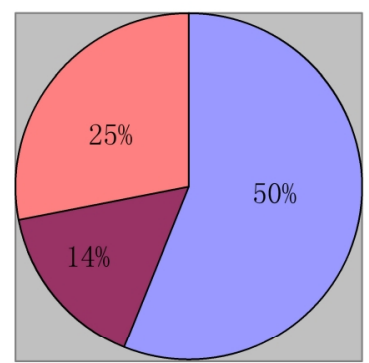

P2

$\square$ Wooden material production

$\square$ Raw material transportation

$\square$ Electricity production

$\square$ Textile production

Fig. 4 Key contribution processes from LCA results 


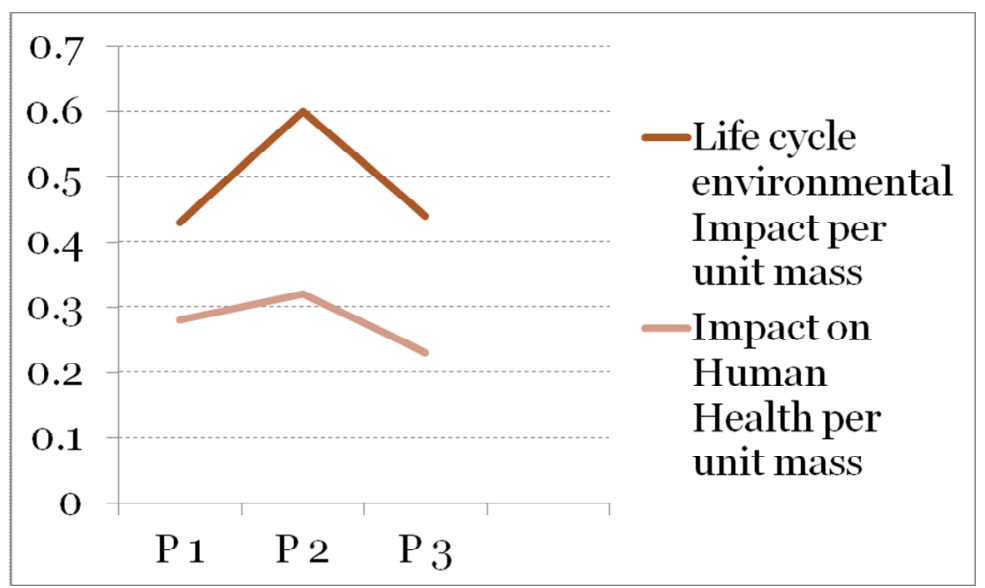

Fig. 5 Environmental impact per unit mass $(\mathrm{kg} / \mathrm{pt})$

As the total mass $(\mathrm{M})$ of the three products are $\mathrm{P} 1_{\mathrm{M}}(50.7 \mathrm{~kg})<\mathrm{P} 2_{\mathrm{M}}(96.1 \mathrm{~kg})<\mathrm{P} 3_{\mathrm{M}}(324.6)$, and the environmental impact index $(\mathrm{I})$ are $\mathrm{P} 1_{\mathrm{I}}(22.1 \mathrm{pt})<\mathrm{P} 2_{\mathrm{I}}(57.3 \mathrm{pt})<\mathrm{P} 3_{\mathrm{I}}(142 \mathrm{pt})$. so the furniture mass is in proportion to its environmental impact index. However, when comparing the environmental impact index in unit $(\mathrm{kg} / \mathrm{pt})$ mass, it shows that $\mathrm{P} 2$, which using various kinds of materials including textiles and infilling materials have the highest index, while value difference between $\mathrm{P} 1_{\mathrm{I}}$ and $\mathrm{P} 3_{\mathrm{I}}$ is only 0.01 , see Fig. 5. In addition, P2 also has the highest value (more negative impact) on Human health in per unit mass. Therefore, the rate of impact value is inversely proportion to volume of material type used in the product. This also suggests that compare to wood material, fabrics or manmade synthetic materials have more negative impact to both eco system and human health.

The potential improvement alternatives could be emphasized on several aspects of solid wood base furniture: reduce the redundant amount of materials in furniture design stage, for example reduce the thickness by conducting FEA; control the volume of multi- type material usage in early design stage; reduce environmental impact by choosing sustainable raw material supplier, including consideration of transport distance. The effectiveness of the alternatives will be assessed in further study.

Table 2 Life cycle environmental impact results

\begin{tabular}{l|c|c|c|c}
\hline \multicolumn{1}{c|}{ Impact Category } & $\mathrm{Unit}$ & $\mathrm{p} 1$ & $\mathrm{p} 3$ & $\mathrm{P} 2$ \\
\hline Total & $\mathrm{Pt}$ & 22.1053 & 142.063 & 57.3303 \\
Carcinogens & $\mathrm{Pt}$ & 0.60437 & 3.32623 & 2.34771 \\
Respiratory organics & $\mathrm{Pt}$ & 0.00562 & 0.02073 & 0.01227 \\
Respiratory inorganics & $\mathrm{Pt}$ & 4.7264 & 25.8341 & 13.0485 \\
Climate change & $\mathrm{Pt}$ & 0.98405 & 4.67743 & 2.86557 \\
Radiation & $\mathrm{Pt}$ & 0.00379 & 0.01113 & 0.00874 \\
Ozone layer & $\mathrm{Pt}$ & 0.00031 & 0.00084 & 0.00068 \\
Ecotoxicity & $\mathrm{Pt}$ & 0.32101 & 1.00942 & 0.6133 \\
Acidification/ Eutrophication & $\mathrm{Pt}$ & 0.33213 & 1.79512 & 1.00911 \\
Land use & $\mathrm{Pt}$ & 10.6233 & 86.9794 & 24.6148 \\
Minerals & $\mathrm{Pt}$ & 0.13578 & 0.14985 & 0.28553 \\
Fossil fuels & $\mathrm{Pt}$ & 4.36851 & 18.2584 & 12.5242 \\
\hline
\end{tabular}

\section{Conclusion}

This work was focused on the comparison of environmental impacts of three solid wood base furniture (a beech desk-P1, a white oak-and-fabric sofa-P2 and a rubber wood wardrobe-P3) through their life cycle. LCA study was conducted by utilizing software tools. 
The LCA results shows that $\mathrm{P} 1$ has the smallest negative environmental impact (22.1 pt) through its life cycle compares to P2 (57.3 pt) and P3 (142 pt). The production of wooden material proved to be the "hot spot" process which contribute $68 \%, 50 \%, 88 \%$ respectively to the total impact of the three subjects', followed by raw material transportation and electricity production.

The comparison of three subjects also reveals that, the furniture mass is in proportion to its environmental impact index; the rate of impact value is inversely proportion to volume of material type used in the product. The conclusion also could be made that compare to wood material, fabrics or manmade synthetic materials have more negative impact to both eco system and human health.

Improvement alternatives have been suggested on improving environmental performance of solid wood base furniture. The result obtained from this study provide valuable data support and insights on material choosing and decision-making for eco-friendly furniture innovation.

\section{References}

[1] information on http://www.mofcom.gov.cn

[2] Petersen AK, Solberg B: Substitution Between Floor Constructions in Wood and Natural Stone: Comparison of Energy Consumption, Green House Gas Emissions, and Costs Over the Life Cycle. Can J Forest Res. Vol. 1061-75 (2003), p. 33

[3] Werner F, Richter K: Wooden Building Products in Comparative LCA, A Literature Review. Int J Life Cycle Assess. Vol. 470-9 (2007).

[4] Bovea M.D., Vidal R.: Materials selection for sustainable product design: A case study of wood based furniture eco-design. Materials and Design. Vol. 25-2 (2004), p. 111-116

[5] González-García S, Feijoo G, Widsten P, Kandelbauer A, Zikulnig Rusch E, Moreira MT: Environmental performance as assessment of hardboard manufacture. Int J Life Cycle Assess. Vol. 14 (2009), p. 546-466

[6] González-García S, Feijoo G, Heathcote C, Kandelbauer A, Moreira M T: Environmental assessment of green hardboard production coupled with a laccase activated system. J Clean Prod. Vol.19 (2011), p.445-453

[7] Sara González-García, Carles M. Gasol, Raúl García Lozano, M Teresa Moreira, Xavier Gabarrell, Joan Rieradevall iPons , Gumersindo Feijoo: Assessing the global warming potential of wooden products from the furniture sector to improve their eco design. Science of the Total Environment. Vol. 12 (2011), p. 16-25

[8] Sara González-García, Raúl García Lozano et al.: Environmental assessment and improvement alternatives of a ventilated wooden wall from LCA and DFE perspective. The International Journal of Life Cycle Assessment. Vol.17 (2012): p. 432-443

[9] MHSPE: Eco-indicator 99 manual for designers (Trans Tech Publications, Netherlands 2000). 